\title{
The Influence of Repeated Motherhood on Periparturitional Behavior in Cynomolgus Macaques (Macaca fascicularis)
}

\author{
P. J. A. Timmermans ${ }^{1,2}$ and J. M. H. Vossen ${ }^{1}$ \\ Received December 22, 1994; revised July 20, 1995; accepted October 30, 1995
}

We studied the influence of parity on periparturitional behavior by quantitatively comparing the behavior of 10 primiparous and 11 multiparous cynomolgus macaques. We found a considerable number of significant differences, some of them affirming the outcome of previous descriptive studies. During the prepartus phase, primiparae showed more locomotion and "action postures" and fewer "resting postures" than multiparae. Further, primiparae spent more time straining than multiparae and were straining in a greater variety of postures than multiparae, which were straining predominantly in a squatting posture. In the postpartus phase, primiparae needed more time than multiparae to get their young in ventroventral position. Primiparae licked mainly the newborn; multiparae licked mainly their own bodies. Finally, fewer primiparae than multiparae ate the placenta. The discussion extensively treats theories concerning parity effects. We explain behavioral differences between primiparae and multiparae in terms of novelty of the female's internal state and novelty of the neonate and in terms of learning. We stress that the mechanism behind the so-called parity effect cannot be revealed without paying more attention, next to learning, to age, to experience with pregnancy, and to experience with parturition. Further, we argue that the immediate acceptance of the newborn at birth and the differences between primiparae and multiparae might play a crucial role in the search for the mechanism behind the onset of maternal behavior.

KEY WORDS: monkey; periparturient behavior; parity; delivery.

${ }^{1}$ Dept. of Comparative and Physiological Psychology, University of Nijmegen, P.O. Box 9104, 6500 HE Nijmegen, The Netherlands.

${ }^{2}$ To whom correspondence should be addressed. e-mail: hilgers@nici.kun.nl. 


\section{INTRODUCTION}

Tinklepaugh, et al. $(1931,1932)$ clearly described the behavior of rhesus monkeys during delivery and characterized parturient behavior of primiparous mothers as restless and confused. Several times thereafter differences between primiparous and multiparous rhesus monkeys have been described in qualitative terms (Brandt and Mitchell, 1971; Goodlin and Sackett, 1983). Often the way primiparous mothers handle neonates has been called awkward.

Quantitative descriptions of parity effects on periparturient behavior were rare until recently. Kemps and Timmermans (1984) and Negayama et al. (1986) assessed quantitative differences in postparturient behavior between primiparae and multiparae. In cynomolgus macaques, Kemps and Timmermans (1984) found that primiparae spend more time manipulating their young and needed more time to take their young in ventroventral position than multiparae, which complement the finding of Negayama et al. (1986) that Japanese macaque primiparae engaged in a greater variety of forms of physical contact with their young than multiparae did. The researchers paid little attention to preparturient behavior.

We present results of a study (with new subjects) on the influence of repeated motherhood on periparturient behavior from the first signs of the oncoming delivery until and including eating the placenta.

\section{METHODS}

We investigated the influence of repeated motherhood on periparturient behavior by comparing the behavior that primiparous and multiparous females displayed some time before, during, and after parturition.

We housed females near the end of the third trimester individually in delivery cages, thereby preventing other members of the group from influencing behavior at delivery. From observations of childbirth in the harem groups, it was clear that females in labor sometimes were harassed by group members. In order to reduce the possible effects of separation from the group, a subject that was living in the delivery cage, was always accompanied by a (pregnant or non-pregnant) harem mate in an adjacent delivery cage. We paired the delivery cages, which were separated from each other by $5-\mathrm{cm}$-mesh wire netting. The delivery cages are $1.50 \times 1.80$ $\times 1.20 \mathrm{~m}$; their floors are $2.5-\mathrm{cm}$ wire netting. The cages are fixed against a wall $1 \mathrm{~m}$ above the floor. In each cage, $70 \mathrm{~cm}$ above the floor, there is a perch $10 \mathrm{~cm}$ wide. Each cage has a food-tray, a water-nipple, and some 
wood blocks. During the night cages are illuminated via a $7-\mathrm{W}$ incandescent lamp fixed above the cage.

We estimated date of childbirth via roentgenographs, interpreted with Hutchinson's (1966) method. Because there is large variation in the length of gestation in cynomolgus macaques (Spiegel, 1950), we put the pregnant females in the delivery cages 3 weeks before expected dates of delivery and observed them regularly via a camera with remote control. If a subject showed signs of imminent delivery, we recorded her on videotape. During nights, when no camera operator was present, the camera was focused so that the entire cage was on screen.

Recording behavior on the videotape started $1.5 \mathrm{hr}$ before childbirth and ended $30 \mathrm{~min}$ after exit of the placenta. In the case of three subjectstwo multiparous females and one primiparous female-because the video recorder was started too late, we could only analyze preparturient behavior for $1 \mathrm{hr}$.

\section{Subjects and Housing}

We observed 10 primiparous and 11 multiparous females. All primiparous animals were born and raised by their mothers in harem groups in our laboratory. At the time of first delivery their ages ranged from 4.5 to 6.0 years. Two multiparous females had been caught in the wild and nine multiparous females had been born in our laboratory and were raised there by their mothers. Before the start of the experiment the multiparous females had already given birth to between three and nine young. Age of the multiparous subjects ranged from 8 to $\sim 20$ years.

Before observations the subjects had lived in cages measuring either $5.0 \times 4.0 \times 2.0$ or $5.0 \times 3.6 \times 2.4 \mathrm{~m}$. We placed each cage in a separate room; and furnished them with horizontal and vertical wooden poles. The floor was covered with wood chips. Water was available ad libitum via drinking-nipples; food (Hope Farms) was provided in the morning and in the evening. Twice per week, the monkeys got cereals or apples or both. A light was on from 0800 until 2000 . Temperature ranged between 18 and $22^{\circ} \mathrm{C}$. Except wild-caught females, the subjects grew up in these facilities.

\section{Parameters}

Usually parturition is divided into phases (Jolly, 1972; Atwood, 1976). We could not use division of the preparturient period into a phase of dilatation and a phase of expulsion, because it was unclear whether dilatatory 
contractions always manifest themselves in overt behavior. We therefore chose a division based on salient changes in the situation of the mother: appearance of the baby and appearance of the placenta. Because these changes strongly influence the behavioral repertoire and the orientation of the mother, we used different behaviors as parameters in each phase.

The first phase is called the preparturient phase. During this phase, behaviors occur that are characteristic of the imminent delivery (Brandt and Mitchell, 1973; Goodlin and Sackett, 1983; Kemps and Timmermans, 1982). We began to record behavior $1.5 \mathrm{hr}$ before childbirth because all mothers were awake and most of them displayed behaviors that are characteristic of this phase. If the position of the fetus is a normal, the preparturient phase finishes with crowning. Because crowning is difficult to observe in freely moving females, we defined the end of the preparturient phase in terms of appearance of the head of the young instead of crowning.

To the parameters, used by Kemps and Timmermans (1984), we added parameters in order to quantify a number of features of primiparous females - restlessness, confusion, and awkwardness - that have been described qualitatively (Tinklepaugh and Hartman, 1931) and cited thereafter (Coe, 1990). During the preparturient phase, we recorded the duration of several exclusive postures and types of locomotion as well as the duration of a number of nonexclusive activities (Table I).

The second phase is the actual partus, which we consider to start with the appearance of the head. Delivery finishes when the baby has completely emerged. Because our investigation concerned only delivery of babies in a normal position, the parturient phase generally was short. Next to the parameters listed in Table II it was recorded whether the mother supported the neonate during expulsion.

The third phase is called the postparturient phase, which we divided into two periods: one period from the birth of the baby until appearance of the placenta and the second for $30 \mathrm{~min}$ after appearance of the placenta. If appearance of the placenta was delayed, the first period ended after $30 \mathrm{~min}$, because by then activity of most mothers strongly decreased. In that case we resumed data collection during $30 \mathrm{~min}$ after appearance of the placenta. After the second period the placenta either had been eaten or was ignored by the mother. We recorded orientation of licking behavior in detail because the results of the research of Kemps and Timmermans (1984) had shown that primiparous and multiparous mothers differ with respect to orientation of licking behavior. The parameters are in Table II. 


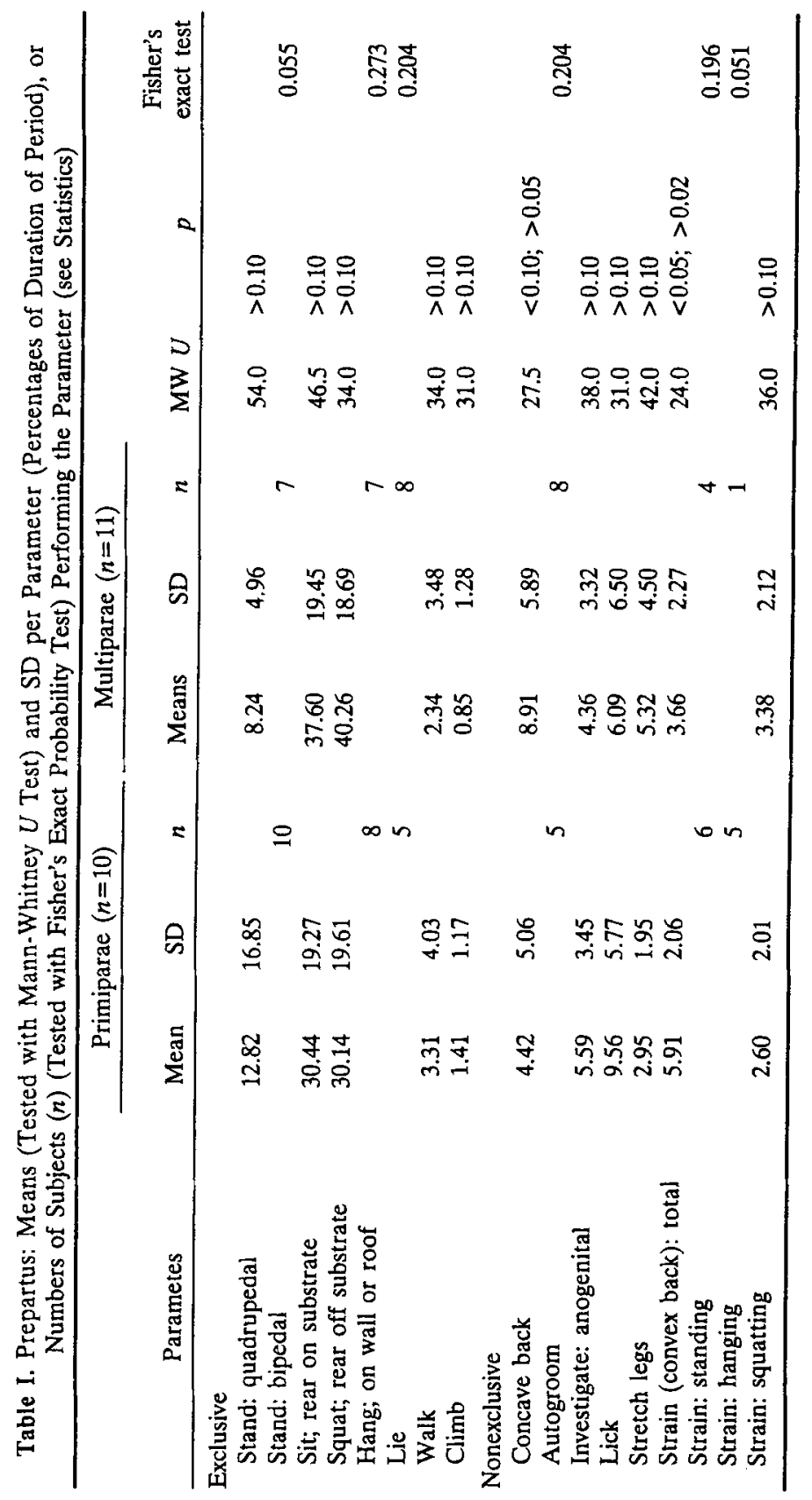




\section{Statistics}

Because in three subjects the duration of the recorded preparturient phase was only $1 \mathrm{hr}$ instead of $1.5 \mathrm{hr}$, we express the duration spent on each behavior as a percentage of the duration of the recorded preparturient period. Because the duration of the period between birth and appearance of the placenta also varied, we express the duration spent on licking (all orientations of licking) as the percentage of the duration of that period. We express durations of autolicking, licking the young, and licking one's own lips, and the substrate on which the animal sat, as percentages of the duration of total orientations of licking. We express the duration of licking the baby's body and the duration of licking its tail as percentages of the duration of total orientations of licking the young. We analyzed data via the Mann-Whitney $U$ test (two-tailed). If more than two subjects of a group scored zero, we used Fisher's exact probability test.

\section{RESULTS}

All fetuses were delivered in normal position and were fully developed. All infants were accepted by their mothers.

\section{Preparturient Phase}

Data concerning the preparturient phase are in Table I; there are significant differences between primiparous and multiparous subjects.

Like other investigators (Brandt and Mitchell, 1973), we noted that primiparous animals were restless and confused during the preparturient phase; all 10 primiparous subjects versus only 7 of 11 multiparous subjects displayed "standing bipedally" (Fisher's exact probability test: $\mathrm{p}=0.055$ ). We grouped data on positional behavior into three categories-action postures (standing quadrupedally and bipedally and hanging), resting postures (sitting, squatting, and lying), and locomotion (walking and climbing) - and found that primiparous females spent significantly more time than multiparous females did in action postures $(U=25 ; 0.05>a>0.02)$ and locomotion ( $U=26 ; a=0.05)$, but spent significantly less time in resting postures $(U=25 ; 0.05>a>0.02)$.

During the preparturient phase licking was directed at amniotic fluid. If the hands of subjects got wet with birth fluid, they licked their hands. But if their hands were soiled with urine or feces, they shook them or wiped them on the substrate. After the membranes had ruptured, three 


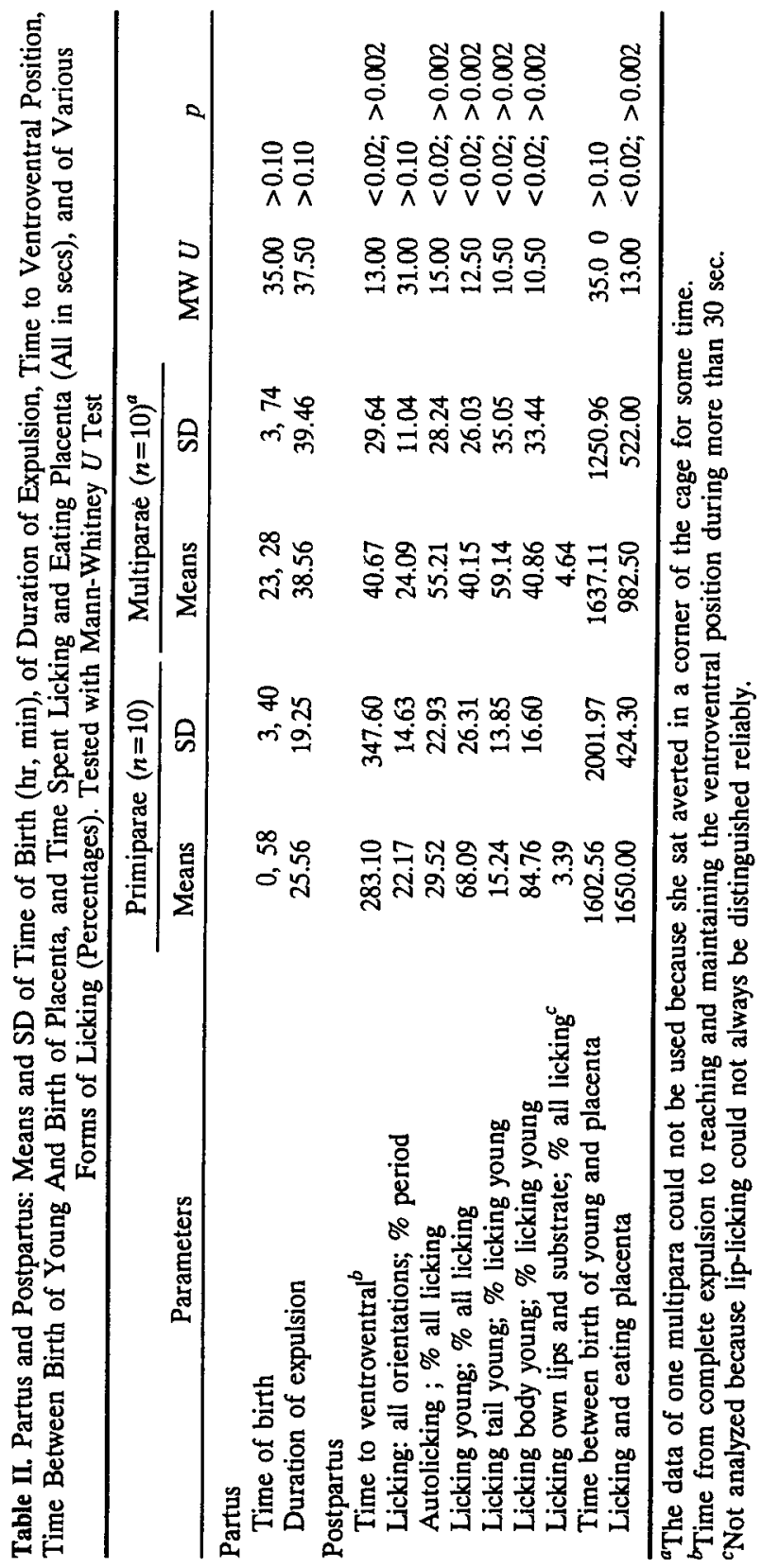


primiparous and four multiparous females also licked the substrate. Four females licked their lips even before the membranes had ruptured. We did not analyze this behavior quantitatively because it could not very well be distinguished on the video recordings that were made without a camera operator.

Duration of straining was longer in primiparous subjects than in multiparous ones $(U=24 ; 0.05>a>0.02)$. The impression of other investigators that primiparous females are confused seems to be in accordance with our observation that during straining, primiparous females behave less stereotypically than multiparous females do. It also seems in accordance with the observation that straining in postures other than squatting more often occurred in primiparous animals than in multiparous ones. All females strained while squatting, but 8 of 10 primiparous females and only 4 of 11 multiparous females strained in other postures: (hanging or standing or both) (Fisher's exact probability test: $p=0.05$ ). Remarkably, the group of primiparous females passed more than half the straining time hanging or standing (Table I). Two primiparous females even strained predominantly while hanging; four primiparous females had contractions predominantly while standing. Contrarily, multiparous females adopted these postures $\leq 10 \%$ of the time they were straining.

\section{Partus}

Data on parturition are in Table II. During parturition we observed no effects of parity. Except one primiparous female that gave birth at 1723 and one multiparous female that gave birth at 1953, all deliveries occurred during the dark period. The mean time of birth for both groups combined is shortly after midnight. All females gave birth while squatting; during delivery they supported the baby with one or both hands from the moment its head appeared. Duration of expulsion was short: 3-113 sec. Duration of delivery was short because we took the appearance of the head and not crowning as the starting point. Mothers typically lowered their heads toward the infants, as if looking at or smelling them, while lifting them from between their thighs (Fig. 1).

\section{Postparturient Phase}

We present the behaviors during the postparturient period in Table II; there are significant differences between primiparous and multiparous mothers. 


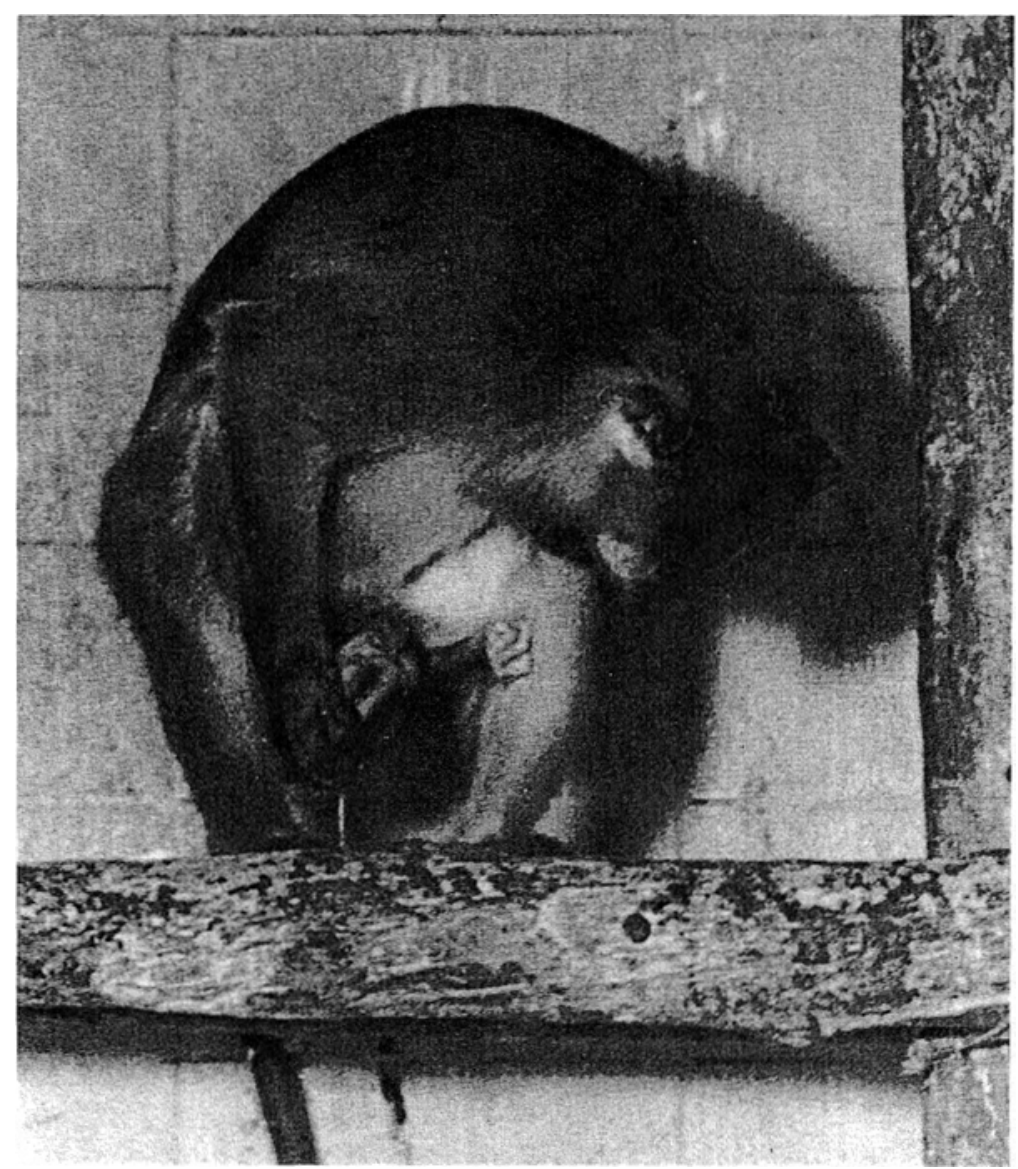

Fig. 1. Cynomolgus mother watching and supporting her baby at birth.

Although immediately after birth all babies tried to cling to their mothers, both primiparous and multiparous females immediately took hold of them with both hands. Multiparous subjects brought their babies into a ventroventral position much sooner than primiparous mothers did $(U=13$; $0.02>a>0.002$ )

Time until the baby reached the ventroventral position seemed to depend upon the mother's skill: primiparous mothers were less skilful than multiparous ones. During delivery, one primiparous female seized the shoulders of her baby with one hand to the right of her thighs and with the other hand to the left of her thighs. She then continued to squat 
on the pole and maintained this constraining posture for many minutes. Finally, she successfully lifted up the baby by releasing her right hand and moving it to her left side, then using both hands to take the baby from beneath her thighs. Another primiparous mother took hold of the neonate with both hands from beneath the pole upon which she was squatting and then could not move because the umbilical cord was twisted around the pole. The baby of another primiparous subject got hold of the wire netting shortly after birth; for many minutes the mother was not able to disengage it.

Five primiparous subjects and two multiparous subjects laid down their young for a few minutes but without unhanding it. The mothers were sitting on the cage floor; this never occurred while they sat on the pole. Primiparous mothers more than multiparous mothers loosened the clasping young from their bodies and kept it in their hands in front of themselves. Putting down the young as well as holding it in front often was accompanied by licking its body. Babies that had no physical contact with the mother would clasp anything within reach. Usually they caught the head, arms, or legs of the mother. Primiparous mothers mostly tried to free themselves by pulling the baby free, while multiparous mothers usually maneuvered the baby into a ventroventral position, after which the young kept quiet.

Primiparous mothers were less successful than multiparous mothers in freeing the hands and the feet of their babies because they usually pulled at the arm or the leg of the young, resulting in even fiercer clinging. Contrarily, multiparous mothers usually took the hand or foot of the infant, which then generally reacted by letting go to cling to the mother's hand. Multiparous mothers mostly moved the young by shifting it on her body, while primiparous mothers often tried to pull the baby free before moving it.

There is no difference between primiparous and multiparous mothers in the total durations of licking in all orientations. All females licked their young and, except for one primiparous mother, also their own body. Primiparous mothers licked the young significantly more and their own bodies significantly less than multiparous mothers did (respectively, $U=12.5,0.02$ $>a>0.002 ; U=15 ; 0.02>a>0.002$ ). Primiparous mothers often held the infant manually while licking it, whereas multiparous mothers usually kept them close to their own bodies and alternately licked the baby and their own hands, arms, and legs.

Primiparous and multiparous females also differ with respect to the distribution of licking on the infant's body. Primiparous mothers licked the baby's tail significantly less and the rest of its body significantly more than multiparous mothers did (in both cases $U=10.5,0.02>a>0.002$ ). Multiparous mothers occasionally took the tail of the baby, while it rested 
ventroventrally, in order to lick it thoroughly. Primiparous mothers distributed licking more equally over all parts of the infant's body.

Primiparous and multiparous mothers do not differ with respect to the length of the period between birth of the young and appearance of the placenta. The strikingly large interindividual differences $(5-118 \mathrm{~min})$ are not the result of differences in duration of its expulsion, which occurred with a few relatively weak contractions.

Multiparous mothers resolutely handled the placenta. During its expulsion they grasped it and immediately licked and ate it while the baby rested in a ventroventral position. Primiparous mothers had problems in handling the baby and the placenta concurrently; the placenta often slipped from their hands. Sometimes the placenta, which was still attached to the baby, caught on a knot in the pole and restricted the mother's movement.

All multiparous mothers ingested some of the placenta; within $30 \mathrm{~min}$ seven of them ate it entirely. In contrast, no primiparous mother ate the placenta entirely in $30 \mathrm{~min}$. Two subjects ingested no placenta, but one of them licked it. The observation that primiparous mothers spent significantly more time licking and eating the placenta $(U=13 ; 0.02>a>0.002)$ indicates hesitancy. Multiparous mothers ate greedily, putting big pieces of placenta into their cheek-pouches, whereas primiparous mothers often only nibbled it. The morning after delivery, no placenta remained in the cages of multiparous mothers, but parts were in the cages of 6 of 10 primiparous mothers. Parts of the placenta hung from ventra of the babies of four primiparous mothers, indicating that primiparous mothers often also omitted biting through the umbilical cord.

All mothers independently raised their young.

\section{DISCUSSION}

Primiparous mothers differ from multiparous mothers with respect to preparturient and postparturient behavior.

During the preparturient phase, primiparous mothers spent more time in locomotion and on action postures but less time in resting postures than multiparous mothers did. These quantitative differences complement Tinklepaugh's and Hartman's (1931) observation that primiparous macaque mothers are restless. But multiparous mothers are not quiet. Both primiparous and multiparous mothers are restless before and during prepartus; they move more and change their postures more often than usual. Restlessness therefore is considered one of the few useful criteria for predicting a delivery [Brandt and Mitchell (1973) and Adachi et al. (1982) rhesus macaques; Goodlin and Sackett (1983) pigtailed macaques]. Perhaps 
primiparous mothers are more restless because they are undergoing the physiological changes that accompany parturition for the first time.

Primiparous females spent more time straining than multiparous females did. This could indicate that in cynomolgus macaques, like rhesus macaques (Brandt and Mitchell, 1971) and humans (Atwood, 1976), the dilatatory stage lasts longer in primiparous than in multiparous females. Further, multiparous females almost exclusively strained while squatting, whereas primiparous females, on an average, spent $>50 \%$ of the time straining in hanging or standing postures. Brandt and Mitchell (1973) also saw a primiparous rhesus female strain while hanging. The primipara's postural changeability during expulsion seems to correspond with the impression of Tinklepaugh and Hartman (1932) that primiparous females are confused. It could be that females learn to adapt their postures to the consequences of uterine contractions.

Primiparous and multiparous females do not differ with respect to anogenital investigation. This behavior already occurred before the membranes had broken and presumably is an immediate reaction to local irritation not susceptible to parity effects. We also observed anogenital investigation in monkeys with rectal prolapse.

We also found no parity effect for the total time spent licking. Some females were lip-licking before the membranes broke, which suggests that this behavior is triggered by endogenous stimuli. Kendrick et al. (1991) found that in sheep, licking of amniotic fluid can be evoked by vaginocervical stimulation. Kemps and Timmermans (1984) also observed lip-licking. After the membranes had broken, licking was directed exclusively to places soiled with amniotic fluid (limbs and substrate), which in the case of primiparae indicates that the fluid acted as an unconditioned appetitive stimulus. After touching the anogenital area, females often smelled the hand and if it was soiled with urine or feces they wiped or shook it, but if smeared with birth fluid, they licked it. Sheep and goats refuse to lick amniotic fluid, except during the period of delivery. In monkeys very little is known about licking amniotic fluid outside the period of delivery. Tinklepaugh and Hartman (1931) mentioned a pregnant rhesus monkey that 35 days preterm showed no interest in amniotic fluid from a conspecific but licked the fluid 3 days preterm. We observed juveniles smelling and tasting birth fluid during a delivery in a harem group during the light period.

Kemps and Timmermans (1984) observed only the last $5 \mathrm{~min}$ of prepartus and found no parity effects. This could be due to the short observation period, but it is also possible that the behavior of the parturient female becomes more and more stereotyped as parturition is drawing near. In any case, all cynomolgus females delivered in a squatting posture. 
Primiparous and multiparous females do not differ concerning the time and duration of parturition. Kemps and Timmermans (1984) also found no parity effect for birth duration and Suzuki et al. (1990) found (no parity effect (in cynomolgus) for the time of birth.

Both primiparous and multiparous mothers supported their infants during expulsion, and immediately held them. Kemps and Timmermans (1984) also found no difference and Brandt and Mitchell (1971), and Goodlin and Sackett (1983) did not distinguish between primiparous and multiparous mothers in rhesus and pigtailed macaques, respectively. Further, Negayama et al. (1986) found no parity effect in Japanese macaques concerning latency until the neonate was seized.

Multiparous mothers brought their infants into ventroventral position much sooner than primiparous mothers did, which was also found by Kemps and Timmermans (1984) and corresponds with various descriptions [Nissen and Yerkes (1943) for chimpanzees; Brandt and Mitchell (1971) for rhesus macaques; Goodlin and Sackett (1983) for pigtailed macaques]. Further, Negayama et al. (1986) found that in Japanese macaques, primiparous mothers engaged in a greater variety of forms of physical contact with their infants than multiparous mothers did. Primipara are awkward in handling their offspring. We often saw primiparous mothers getting entangled in their own limbs and having trouble negotiating the grasping and clinging reflexes of their infants. With respect to these differences between primiparae and multiparae, an explanation in terms of operant conditioning seems plausible.

In addition to awkwardness, other factors might play a role. For a primipara, physical contact with a neonate is a novel experience, since she had no previous contact with neonates and because she has a novel internal condition. Kemps and Timmermans (1984) interpreted the finding that primiparous mothers spent more time handling the neonate than multiparous mothers did as an appetitive reaction to novelty. However, novelty can also elicit avoidance or a conflict between approach and avoidance (Montgomery, 1955). In his model of the regulation of maternal motivation (based on data from rat, sheep, and rhesus macaques), Pryce (1992) distinguished four factors: attraction and anxiety versus aversion and fear of novelty. Further, there is firm evidence that inexperienced females of various species have to habituate to neonates: avoidance of pups occurs in nulliparous rats (Terkel and Rosenblatt, 1971; Fleming, 1986) and primiparous sows sometimes aggressively react to their first born piglets (Schouten, personal communication). Newborn primates apparently possess aversive qualities. It is not uncommon for primiparous chimpanzees to react to their young with fear and avoidance, or with ambivalence (Rogers and Davenport, 1970). Nulliparous rhesus females refused to retrieve sucklings 
during adoption tests (Holman and Goy, 1980); primigravid females refused to do so even during pregnancy and during the preparturient period (Gibber, 1986). With respect to delivery, Negayama et al. (1986 p. 366) remarked that "a female has to adjust herself abruptly when a strange neonate suddenly appears close to her." Further, Tanaka (1989) found that primiparous Japanese macaques often did not tolerate their infants taking the teat during the first day after parturition. Contrarily amniotic fluid seems to act as an unconditioned appetitive stimulus because primiparous mothers licked no less than multiparous ones did.

Comparing the manipulations with neonates by primiparous and multiparous mothers, one might say that the primipara keeps her offspring at a distance without losing hold of it, whereas the multipara embraces her offspring. It may be that the primipara initially more or less tolerates the neonate's attempts to cling in order to have the opportunity to continue licking amniotic fluid which she started to do after the membranes broke. Meanwhile, she habituates to being clasped by the infant and gradually allows it to cling to her belly. The clinging efforts initially seem to stimulate the mother to keep her young at a distance; however, clinging prevents the young from falling in case the mother is very awkward.

Our interpretation also offers an explanation for the finding that primiparous mothers predominantly licked their young, whereas multiparous mothers predominantly licked their own limbs. Contrary to primiparous mothers, multiparous ones had ample opportunity to lick their limbs because they permitted their infants to cling to their ventra within a minute after birth. We also found that primiparous mothers mainly licked their infants' trunks, while multiparous mothers mainly licked their infants' tails. This too might be a consequence of the infant's position on the mother. Holding infants ventroventrally, multiparous mothers could use their hands to seize the infant's tail where amniotic fluid was gathering as a result of its posture.

All multipara ate the whole placenta, most of them within $30 \mathrm{~min}$, which no primipara achieved. Still, primiparous mothers spent more time eating from the placenta and licking it than multiparous mothers did. This difference could be a consequence of its novelty. When we offered novel food-eggs, bread, bananas-to our laboratory born monkeys, they initially were very reluctant to consume it but soon came to like it.

Some have assumed that placentophagia promotes the onset of maternal behavior (Higley and Suomi, 1986). Eating the placenta and severing the umbilical cord are supposed to be followed by licking the neonate, which would identify one's own infant. However, this reasoning ignores the actual sequence of behavior. The placenta emerges later than the infant by which time it often has been licked clean and is quietly sitting in ven- 
troventral position. In free-ranging conditions, postponing maternal care until after placentophagia could mean dropping and losing the neonate. Further, we found that most primiparous mothers ate only part of the placenta, and some of them nothing at all, yet they adequately cared for their young. Negayama et al. (1986) described the behavior of a primipara that, though devouring the placenta, did not accept its infant, which lay on the floor of the cage. We agree with Higley and Suomi (1986) that not eating the placenta is no hindrance to maternal care. Finally, identifying the infant as one's own immediately after delivery, as occurs in sheep (Alexander $e t$ al., 1986), would have no function in macaques because they constantly keep their young with them during the first weeks.

Coe (1990) summarized other presumed functions of placentophagia: (1) obtaining hormones that facilitate lactation and, inhibit uterine bleeding, (2) separation of placenta and infant, which prevents bleeding of the umbilical cord, (3) preventing discovery by a predator, and (4) feeding and quenching the exhausted mother. Our results do not support the first two hypotheses. Though several primiparous mothers did not eat placenta and many of them ate it only partially, we never found insufficient lactation or uterine bleeding in primiparous mothers; neither did we notice umbilical bleeding. Further, effects of placentophagia on lactation could not be demonstrated (Naaktgeboren, 1979). It seems implausible that discovery by predators is prevented by placentophagia because feces, urine, amniotic fluid, and blood lost during parturition would be present, which could attract predators.

Placentophagia may be feeding behavior. Macaques are opportunistically omnivorous (McKenna, 1982). The placenta is nutritious and the mother has to nurse her offspring. Further, we observed that multiparous mothers avidly devoured the placenta and that dominant females stole and ate the placenta from submissive mothers. During parturition of a toque macaque in the wild, the alpha female usurped the mother and ate part of the placenta (Ratnayeke and Dittus, 1989).

Several primiparous mothers did not bite through the umbilical cord so that the placenta or part of it dangled from the infant the next morning. This was also observed by Kemps and Timmermans (1984) who further noticed that multiparous mothers handled the placenta better than primiparous mothers did. This difference probably reflects a difference in the way the infant is cared for; holding the infant ventroventrally, the multipara has her hands free, whereas the primipara has her hands full holding. Further, multiparous mothers seemed more motivated to eat the placenta.

Despite a number of significant differences, primiparous and multiparous mothers are equally successful in rearing their young (Timmermans and Vossen, 1996). Seay (1966) also found that in rhesus macaques there 
is no difference between primiparae and multiparae concerning the adequacy of care-taking. Nevertheless, awkward and prolonged manipulations of primiparous mothers with their neonates and with placentas sometimes led to problematic situations that could have endangered the infant's life in a natural setting. There are several studies indicating that primiparae lose more infants than multiparae do (Drickamer, 1974), but it is unclear whether awkward handling after delivery or later plays a part.

How does the parity effect come about? Behavioral differences between primiparous and multiparous mothers are ascribed mostly to experience in dealing with infants, but questions of what is learned and in what way, generally are passed over. One prerequisite for learning to occur is, of course, that the mother does not immediately lose her infant or that her infant is not immediately taken away from her because her behavior is inadequate. This means that only if the primiparous mother, at the moment of child birth, immediately performs the essential manipulations to keep her infant can she learn about infant care. Timmermans and Vossen (1996) concluded that the essential manipulations that occur at birth are performed by primiparae without previous practice. If the primipara meets this requirement, then learning ad hoc how to hold the neonate properly and allow it to move to the ventroventral position, or to bring it in that position, seems possible. Resistance from the infant when it is not in the ventroventral position and the comfortable position of the mother when it is in the right position could act as reinforcers. Rogers and Davenport (1970) suggested about how a baby chimpanzee could shape its mother's behavior. This experience, acquired while in the physiological state of parturition, could benefit the next delivery. Further, the experience acquired while the infant is growing up also could affect behavior during the next delivery. With respect to severing the umbilical cord and placentophagia, there also are possibilities for ad hoc learning, the results of which could affect behavior when the next infant is born.

However, in some cases it has been explicitly mentioned that mothers adequately cared for their second infants, although they did not touch their firstborn. The cases include one cynomolgus monkey (Timmermans and Vossen, 1996), and several chimpanzees (Nissen and Yerkes, 1943; Rogers and Davenport, 1970; Coe, 1990). Coe (1990) remarked that such cases deserve more attention. In such cases, adequate behavior with the second infant cannot depend on learning with the first one. Of course another prerequisite for learning is that the primipara which stays with her infant performs true maternal behavior. Among solitarily-reared rhesus females (Ruppenthal et al., 1976), indifferent mothers had the opportunity to interact with their firstborn infants for a few days during some hours a day. Although paying no attention to their firstborn, they often accepted their 
next infants. These cases demonstrate that maternal behavior can change from nonacceptance of the infant as a primipara into acceptance and adequate care of the infant as a multipara without interference of experience with caring for infants

Whether mothers that refused to accept their firstborn but accepted their second infant handled their second infants like primiparae or like multiparae cannot be answered due to lack of data. In one case Negayama $e t$ al. (1986) took away the firstborn of a Japanese macaque $30 \mathrm{~min}$ after birth because the mother did not accept it; she awkwardly accepted her second infant.

There are other ambiguities regarding the part experience with the firstborn plays in the origin of the parity effect. Though age is probably a relevant factor, this variable, like experiences with pregnancy and parturition, has been studied minimally in monkeys (Pryce, 1995). Meier (1965) remarked that it is not clear whether experience or maturation is the more important factor with respect to the development of adequate maternal behavior in rhesus monkeys. In a group of free-ranging rhesus monkeys, Drickamer (1974) assessed that young had lower chances of survival when their mothers were 3-5 years old than if they were 6 years old, but he provided no behavioral data. Sackett \& Ruppenthal (1974) concluded that 8 -year-old laboratory-born macaques were attracted to infants irrespective whether they had or had no prior offspring. Nulliparous rhesus monkeys generally avoid sucklings. Ruppenthal et al. (1976) noted that indifferent mothers were older at first delivery than abusive mothers and suggested that full maturity could have ameliorated abusive behavior. They also found that primiparous mothers were superior at the age of 8 years and suggested that full maturation of the hormonal system could be achieved then. Negayama et al. (1986) suggested that parity differences could be due in part to age. Finally, Nicolson (1991) proposed a mechanism to explain an age effect: reproductive maturity might have been accelerated by nutritional supplementation leading to asynchrony between physical and social development (Altmann, 1985).

Holman and Goy (1980) suggested a crucial role for pregnancy and delivery to explain behavioral differences between primiparae and multiparae. They found that most multiparous rhesus macaques carried sucklings, regardless of their hormonal state (cycling, menopausal, or ovariectomized), whereas all nulliparous females refused to do so. They further suggested that during the first parturition, a hormone-dependent imprinting or learning process might occur. Concerning the variable repeated delivery, it is conceivable that the novelty of the internal condition prevailing during delivery affects primiparal behavior. This phenomenon might also explain other differences between primiparous and multiparous 
mothers. In rats, changes in the magnocellular neurons of the hypothalamic-neurohypophyseal system occurred during delivery and some of them were permanent (Modney and Hatton, 1990).

We conclude that primiparous mothers behaved less efficiently and less skillfully than multiparous mothers did during the preparturient and postparturient periods. Primiparous mothers seemed to be as motivated as multiparous mothers are to investigate and to lick prepartum, and to take hold of and to lick the neonate, but less motivated to immediately hold the neonate ventroventrally and less motivated to eat the placenta. Current evidence does not justify conclusions concerning the mechanisms behind these differences. Free-ranging primiparae may lose more offspring than multiparae do because of awkward and prolonged manipulations with the newborn and its placenta.

\section{ACKNOWLEDGEMENTS}

We thank J. C. M Krijnen for his dedicated assistance in recording deliveries, A. Oomen for collecting data, members of the staff of the Central Animal Laboratory (CDL) for estimating delivery dates, and Dr. J. Receveur for correcting the English version of the manuscript. Part of the studies reported was supported by Grants 15-25-05, 15-25-16, and 560-258033 from the Foundation for Behavioral Sciences of The Netherlands' Organization for Scientific Research (NWO) awarded to the authors.

\section{REFERENCES}

Adachi, M., Saito, R., and Tanioka, Y. (1982). Observation of delivery behavior in the rhesus monkey. Primates 23: 583-586.

Alexander, G., Poindron, P., Le Neindre, P., Stevens, D., Levy, F. and Bradley, L. (1986). Importance of the first hour post-partus for exclusive maternal bonding in sheep. Appl. Anim. Behav. Sci 16: 295-300.

Altmann, J. (1985). Adolescent pregnancies in non-human primates: An ecological and developmental perspective. In Lancaster, J., and Hamburg, B. (eds.), School-Age Pregnancy and Parenthood: Biological Dimensions, Aldine, New York, pp. 247-262.

Atwood, R. J. (1976). Parturitional posture and related birth behavior. Acta Obstet. Gynecol. Scand. Suppl. 57: 1-25.

Brandt, E. M., and Mitchell, G. (1971). Parturition in primates: Behavior related to birth. In Rosenblum, L.A. (ed.), Primate Behavior Developments in Field and Laboratory Research, Academic Press, New York, pp. 177-223.

Brandt, E. M. and Mitchell, G. (1973). Labor and delivery in rhesus monkeys (Macaca mulatta). Am. J. Phys. Anthropol. 38: 519-522.

Coe, C. L. (1990). Psychobiology of maternal behavior in nonhuman primates. In Krasnegor, N. A, and Bridges, R. S. (eds.), Mammalian Parenting, Oxford University Press, New York, pp. 157-182. 
Drickamer, L. C. (1974). A ten year summary of reproductive data for free-ranging macaca mulatta. Folia Primatol. 21: 61-80.

Fleming, A. S. (1986). Psychobiology of rat maternal behavior. How and where hormones act to promote maternal behavior at parturition. Ann. N. Y. Acad. Sci 474: 234-251.

Gibber, J. R. (1986). Infant-directed behavior of rhesus monkeys during their first pregnancy and parturition. Folia Primatol. 46: 118-124.

Goodlin, B. L., and Sackett, G. (1983). Parturition in macaca nemestrina. Am. J. Primatol. 4: 283-307.

Higley, J. D., and Suomi, S. J. (1986). Parental behavior in non-human primates. In Sluckin, W., and Herbert, M. (eds.), Parental Behavior, Blackwell, Oxford, pp. 152-207.

Holman, S. D., and Goy, R. W. (1980). Behavioral and mammary responses of adult female rhesus to strange infants. Horm. Behav. 14: 348-357.

Hutchinson, T. C. (1966). A method for determining expected parturition date of rhesus monkeys (Macaca mulatta). Lab. Anim. 16: 93-96.

Jolly, A. (1972). Hour of birth in primates and man. Folia Primatol. 18: 108-121.

Kemps, A., and Timmermans, P. (1982). Parturition behavior in pluriparous Java macaques (Macaca fascicularis). Primates 23: 75-88.

Kemps, A., and Timmermans, P. (1984). Effects of social rearing conditions and partus experience on periparturitional behavior in Java macaques (Macaca fascicularis). Behaviour 88: 200-215.

Kendrick, K. M., Lévy, F., and Keverne, E. B. (1991). Importance of vaginocervical stimulation for the formation of maternal bonding in primiparous and multiparous ewes. Physiol. Behav. 50: 595-600.

McKenna, J. J. (1982). The evolution of primate societies, reproduction, and parenting. In Fobes, J. L., and King, J. E. (eds.), Primate Behavior, Academic Press, New York, pp. 87-128.

Meier, G. W. (1965). Other data of the effects of social isolation during rearing upon adult reproductive behavior in the rhesus monkey (Macaca mulatta). Anim. Behav. 13: 228-231.

Modney, B. K., and Hatton, G. I. (1990). Motherhood modifies magnocellular neuronal interrelatioships in functional meaningful ways. In Krasnegor, A., and Bridges, S. (eds.), Mammalian Parenting. Oxford University Press, Oxford, pp. 286-321.

Montgomery, R. C. (1955). The relation between fear induced by novel stimulation and exploratory behavior. J. Comp. Physiol. Psychol. 48: 254-269.

Naaktgeboren, C. (1979). Behavioral aspects of parturition. Anim. Reprod. Sci. 2: 155-166.

Negayama, K, Negayama, T., and Kondo, K. (1986). Behavior of Japanese monkey (Macaca fuscata) mothers and neonates at parturition. Int. J. Primatol. 7: 365-378.

Nicolson, N. A. (1991). Maternal behavior in human and nonhuman primates. In Loy, J. D., and Peters, C. D. (eds.), What Primate Studies Tell Us About Human Behavior, Oxford University Press, pp. 15-50.

Nissen, H. W., and Yerkes, R. M. (1943). Reproduction in the chimpanzee: Report on forty-nine births. Anat. Rec. 86: 567-578.

Pryce, C. R. (1992). A comparative systems model of the regulation of maternal motivation in mammals. Anim. Behav. 43: 417-441.

Pryce, C. R. (1995). Determinants of motherhood in human and nonhuman primates: A biosocial model. In Pryce, C. R., Martin, R. D., and Skuse, D. (eds.), Motherhood in Human and Nonhuman Primates: Biosocial Determinants, Karger, Basel, pp 1-15.

Ratnayeke, A. P., and Dittus, W. P. J. (1989). Observation of a birth among wild toque macaques (Macaca sinica). Int. J. Primatol. 10: 235-242.

Rogers, C. M., and Davenport, R. (1970). Chimpanzee maternal behavior. In Bourne, G. H. (ed.), The Chimpanzee, 3, Karger, Basel, München, New York, pp. 361-368.

Ruppenthal, G. C., Arling, G. L., Harlow, H. F., Sackett, G. P., and Suomi, S. J. (1976). A ten year perspective of motherless mother monkey behavior. J. Abnorm. Psychol. 85: 341-349.

Sackett, G. P., and Ruppenthal, G. C. (1974). Some factors influencing the attraction of adult female macaque monkeys to neonates. In Lewis, M., and Rosenblum, L. A. (eds.), The Effect of the Infant on its Caregiver, Wiley, New York, pp. 163-185. 
Seay, B. (1966). Maternal behavior in primiparous and multiparous rhesus monkeys. Folia Primatol. 4: 146-168.

Spiegel, A (1950). Weitere Beobachtungen und Untersuchungen über die Fortpflanzung bei Javamakaken. Archiv. Gynaekol. 177: 590-629.

Suzuki, M. T., Ono, T., Khono, M., and Ogawa, H. (1990) Hour of delivery in Cynomolgus monkeys under individually caged conditions. Primates 31: 251-255.

Tanaka, I. (1989). Variability in the development of mother-infant relationships among free-ranging Japanese macaques. Primates 30: 477-491.

Terkel, J., and Rosenblatt, J. (1971). Aspects of nonhormonal maternal behavior in the rat. Horm. Behav. 2: 161-171.

Timmermans, P. J. A., and Vossen, J. M. H. (1996). The influence of rearing conditions on maternal behavior in cynomolgus macaques (Macaca fascicularis). Int. J. Primatol. 17: 259-276.

Tinklepaugh, O. L., and Hartman, K. G. (1931). Behavioral aspects of parturition in the monkey (Macaca rhesus). J. Comp. Psychol. 11: 63-98.

Tinklepaugh, O. L, and Hartman, K G. (1932). Behavior and maternal care of the newborn monkey (Macaca mulatta). J. Genet. Psychol. 40: 257-286. 